\title{
An Escherichia coli strain for expression of the connexin45 carboxyl terminus attached to the 4th transmembrane domain
}

\author{
Jennifer L. Kopanic, Mona Al-Mugotir, Sydney Zach, Srustidhar Das, Rosslyn Grosely and Paul L. Sorgen*
}

Department of Biochemistry and Molecular Biology, University of Nebraska Medical Center, Omaha, NE, USA

\section{Edited by:}

Stefan Dhein, Universitätsklinik

Leipzig Herzzentrum Leipzig GmbH,

Germany

Reviewed by:

Steven M. Taffet, SUNY Upstate

Medical University, USA

Gina Sosinsky, University of California

at San Diego, USA

*Correspondence:

Paul L. Sorgen, Department of

Biochemistry and Molecular Biology,

University of Nebraska Medical

Center, 985870 Nebraska Medical

Center, Omaha, NE 68198-5870, USA

e-mail:psorgen@unmc.edu
A major problem for structural characterization of membrane proteins, such as connexins, by nuclear magnetic resonance (NMR) occurs at the initial step of the process, the production of sufficient amounts of protein. This occurs because proteins must be expressed in minimal based media. Here, we describe an expression system for membrane proteins that significantly improves yield by addressing two common problems, cell toxicity caused by protein translation and codon bias between genomes. This work provides researchers with a cost-effective tool for NMR and other biophysical studies, to use when faced with little-to-no expression of eukaryotic membrane proteins in Escherichia coli expression systems.

Keywords: membrane protein expression, rare codons, connexins, NMR, minimal media

\section{INTRODUCTION}

Membrane proteins play a fundamental role in human disease and constitute a major portion of drug targets; lacking is sufficient structural and functional information compared to soluble proteins (Drew etal., 2003; Molina et al., 2008). The limitations can be traced to difficulties in expression, optimizing purification procedures, and reconstituting the proper fold in a lipid environment. Yield is a major problem because only a few membrane proteins are expressed in large-enough quantities to be collected from natural sources. Strategies developed to overcome this problem include engineering vectors to express membrane proteins in S. cerevisiae yeast, Sf9 insect, and Escherichia coli bacteria cell expression systems (Bernaudat et al., 2011).

Escherichia coli is a widely used host for the production of heterologous proteins due to its ability to grow rapidly at high density and in inexpensive substrates (Molina et al., 2008). The E. coli strain BL21 is extensively used for protein expression because it is deficient in lon and ompT proteases (Ratelade etal., 2009). The BL21(DE3) version carries a chromosomal copy of the T7 RNA polymerase gene under control of the lacUV5 promoter, suitable for protein production from target genes cloned into any T7 vector (e.g., pET) by induction with isopropyl- $\beta$-D-thiogalactopyranoside (IPTG; Studier and Moffatt, 1986; Unger et al., 1999). However, problems still arise because bacteria have difficulties folding membrane proteins and expression can be toxic (Miroux and Walker, 1996; Laible et al., 2004). Derivatives of BL21(DE3) called the Walker strains, C41(DE3) and C43(DE3), were therefore created with an enhanced ability to express otherwise toxic membrane proteins (Miroux and Walker, 1996). C41(DE3) was derived from the BL21(DE3) strain through natural selection to survive expression of the oxoglutarate-malate carrier protein from mitochondrial membranes. C41(DE3) has at least one uncharacterized mutation, enabling membrane protein expression into inclusion bodies without toxic effects (Miroux and Walker, 1996). Because expression of other membrane proteins were still toxic in the C41(DE3) strain, C43(DE3) was derived from $\mathrm{C} 41(\mathrm{DE} 3)$ by selecting resistance to the F-ATPase b subunit gene. Thus, C43(DE3) can express a different set of toxic membrane proteins than C41(DE3).

Eukaryotic protein expression by E. coli is also strongly affected by codon bias. The genetic code contains 64 possible nucleotide combinations, which encode 20 amino acids and three codons that terminate translation. The frequencies with which different codons are used, which correlates with the amount of their corresponding tRNAs, vary between organisms (Gouy and Gautier, 1982). For example, eukaryotes commonly use the AGG codon for Arginine, which is rarely used in E. coli (Novy et al., 2001; Gustafsson et al., 2004). Expressing an eukaryotic gene with numerous rare codons in bacteria can impact expression through premature termination of translation, translational stalling, frame shifting, and mis-incorporation of amino acids (Kurland and Gallant, 1996). This problem can be solved by exchanging rare codons in the target gene for more frequently used codons in E. coli or by expressing the rare tRNAs. The latter has been implemented through creation of the BL21(DE3)-derived Rosetta (Novagen) and BL21(DE3)-CodonPlus (Agilent Technologies) strains. These strains contain a plasmid to express eukaryotic tRNAs rarely used in E. coli. For example, the pLysS plasmid within the Rosetta 2(DE3)pLysS strain carries tRNA genes that encode for seven rare codons, including AGG (Novy et al., 2001). Many studies 
have shown that protein expression is enhanced in these strains (Kane, 1995).

Every membrane protein is unique in the challenges needed to obtain a sample viable for structural studies. The increased number of possible methodologies at each step will help save researcher's time and money, and more importantly may provide ideas for future improvements. Previous $\mathrm{Cx} 43$ studies from our laboratory identified that tethering of the CT domain to TM4 was necessary to elicit a change in secondary structure in response to factors known to regulate gap junction channels (Kellezi et al., 2008; Grosely et al., 2013). Therefore, our studies were extended to test the expression of other connexin carboxyl-terminal domains when attached to their 4th transmembrane domain (TM4-CxCT; Cx26, Cx32, Cx37, Cx40, Cx45, and Cx50). This is the first critical step toward structural characterization of their CT domains. These isoforms were chosen for investigated because of their known functional significance and involvement in human disease (for review, see Laird, 2010; Zoidl and Dermietzel, 2010). The protocol developed for TM4-Cx45CT expression will be described in detail, as an example of the TM4-CxCT domains. $\mathrm{Cx} 45$ is highlighted because of the unique expression requirements in comparison to the other isoforms. Cx45 is the first cardiac connexin expressed during embryonic development and plays an important role in propagating the action potential from the conduction system to the working myocardium (Severs et al., 2006; Palacios-Prado et al., 2010). Cx45 gap junction channels close when the membrane potential becomes negative, which has been suggested to prevent retrograde conduction from the myocardium to the conduction system (Palacios-Prado et al., 2010). Cx45 has limited expression in normal, working ventricular myocytes; however, in failing heart tissue, an up-regulation of $\mathrm{Cx} 45$ reduces the cell-tocell coupling while promoting arrhythmogenesis, especially when superimposed on the down-regulation of Cx43 (Yamada et al., 2003; Betsuyaku et al., 2005).

Development of the methods described herein has resulted in protein yields that are at the levels necessary for biophysical characterization (e.g., circular dichroïsm (CD), isothermal calorimetry, etc.), including structural analysis by nuclear magnetic resonance (NMR). This methodology will be of general usage for other intrinsically ordered domains from membrane proteins.

\section{MATERIALS AND METHODS}

\section{GENERATION OF THE TM4-CXCT CONSTRUCTS}

TM4-CxCT domains used in this study were from the Cx50, Cx45, Cx43, Cx40, Cx37, Cx32, and Cx26 isoforms. Table 1 provides the amino acid sequence and species used for each TM4-CT domain to clone and ligate into the pET-14b expression vector (N-terminal $6 \times$ His-tag, ampicillin resistance; Novagen). Each construct includes 10 residues prior to their predicted TM4 domain (e.g., TM4-Cx45CT, Figure 1). All plasmid sequences were verified at the University of Nebraska Medical Center DNA Sequencing Core Facility.

\section{PURIFICATION OF THE TM4-Cx45CT}

Purification of the TM4-Cx45CT was based on the protocol developed for the TM4-Cx43CT domain (Kellezi et al., 2008). Cells were resuspended in $1 \times$ PBS buffer containing a bacterial protease inhibitor cocktail (250 $\mu \mathrm{L} / 4 \mathrm{~L}$ cells; Sigma-Aldrich) and $1 \mathrm{mM}$ $\beta$-mercaptoethanol. Cells were then lysed with an Emulsiflex-C3 (Avestin) for three passages at 15,000 psi. Cell debris was removed with centrifugation $(4,000 \mathrm{rpm}, 1 \mathrm{~h})$ and a pellet containing the inclusion bodies was collected by centrifugation (18,000 rpm, $1 \mathrm{~h}$ ). The pellet was resuspended in $50 \mathrm{~mL}$ Buffer A (6 M urea, $1 \times$ PBS, $20 \mathrm{mM}$ imidazole, and $1 \mathrm{mM} \beta$-mercaptoethanol, $1 \%$ Triton $\mathrm{X}-100, \mathrm{pH} 8.0)$ and rocked overnight at $4^{\circ} \mathrm{C}$. The suspension was centrifuged again $(18,500 \mathrm{rpm}, 1 \mathrm{~h})$, and the supernatant was loaded onto an ÄKTA FPLC using a HisTrap HP column (GE Healthcare). Protein elution was accomplished using a step gradient $(4,8,10,30$, and $50 \%)$ of Buffer B (6 M urea, $1 \times$ PBS, $1 \mathrm{M}$ imidazole, $1 \mathrm{mM} \beta$-mercaptoethanol, and $1 \%$ Triton $\mathrm{X}-100, \mathrm{pH} 8.0$ ). Fractions that contained the $22 \mathrm{kDa}$ His-tagged TM4-Cx45CT protein (verified by SDS-PAGE and Western blot analyses) were pooled and dialyzed overnight at $4^{\circ} \mathrm{C}$ using a 10,000 MW cut off Slide-A-Lyzer dialysis cassette (Pierce) against buffer C [1 M urea, $1 \mathrm{mM}$ dithiothreitol (DTT), $1 \mathrm{mM}$ EDTA, and $1 \%$ Triton $\mathrm{X}-100]$. The precipitate was collected and centrifuged (4,000 rpm, $5 \mathrm{~min})$, washed twice with water then buffer D (20 mM MES buffer, $1 \mathrm{mM}$ DTT, $1 \mathrm{mM}$ EDTA, and $50 \mathrm{mM} \mathrm{NaCl}$, $\mathrm{pH}$ 5.8). The washed precipitate was then solubilized in buffer $\mathrm{E}$ (20 mM MES, 1 mM DTT, 8\% 1-palmitoyl-2-hydroxy-sn-glycero3-[phospho-RAC-(1-glycerol)] (LPPG; Avanti Lipids), and $1 \mathrm{mM}$

Table 1 | Conditions used to produce NMR samples for each TM4-CxCT construct.

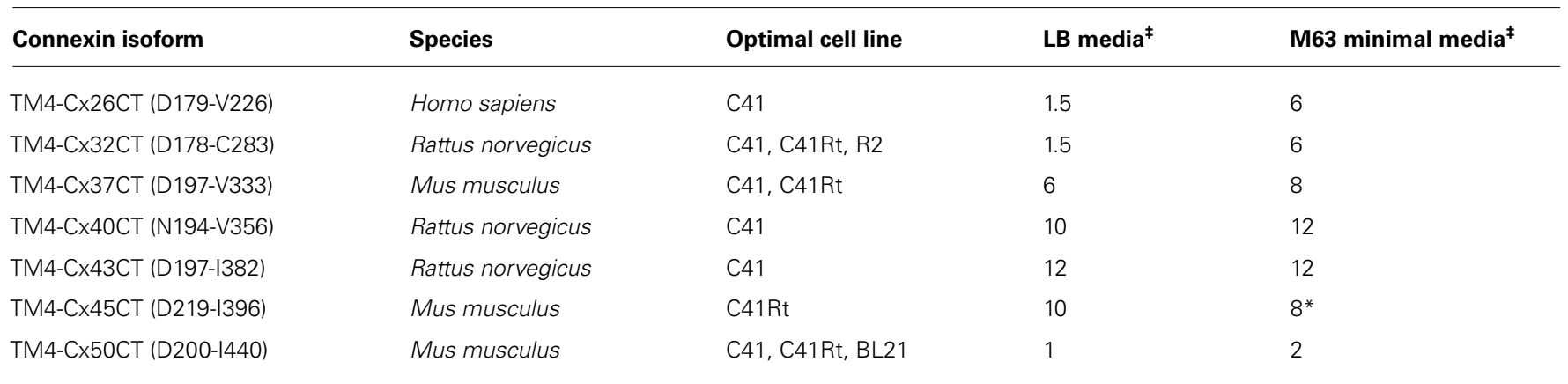

Abbreviations used for E. coli competent cell stains: C41, C41(DE3); R2, Rosetta2(DE3)pLysSRARE2; C41Rt, C41(DE3)pLys; BL21, BL21(DE3).

${ }^{\ddagger}$ Liters of bacterial culture required to produce a $300 \mu \mathrm{L}$ sample at $1 \mathrm{mM}$ concentration.

*ISOGRO required for TM4-CX45CT expression in minimal media. 


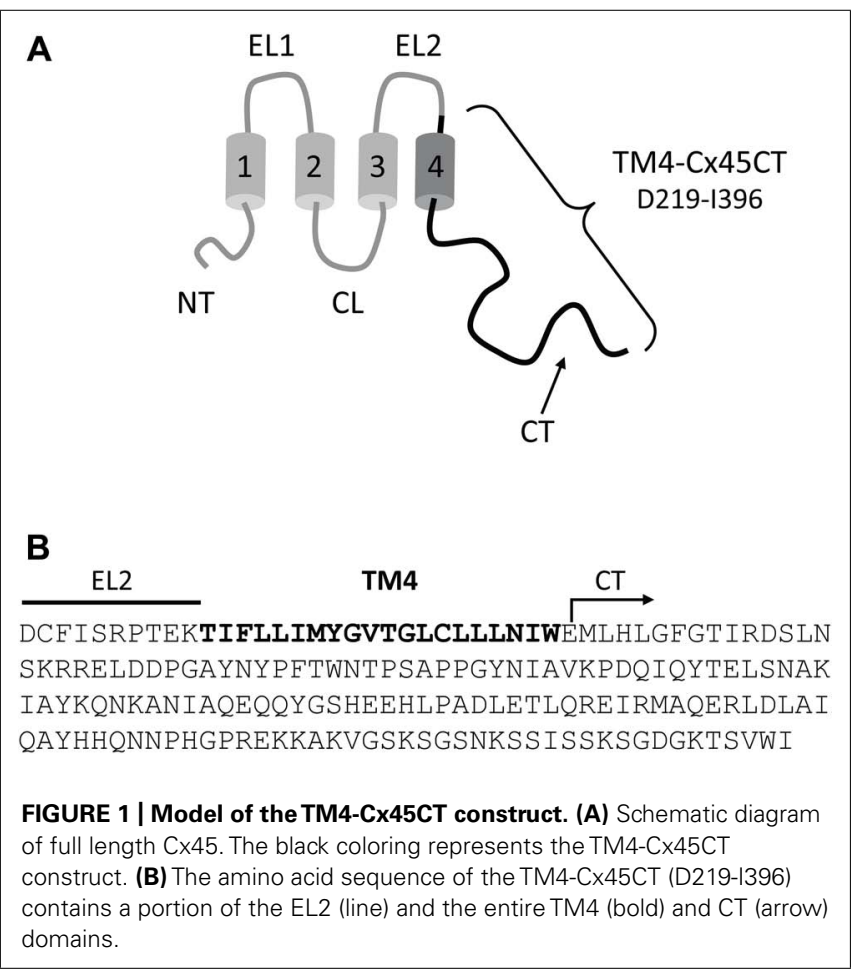

EDTA) and incubated at $42^{\circ} \mathrm{C}$ for $30 \mathrm{~min}$. Buffer $\mathrm{E}$ was used for all TM4-Cx45CT experiments.

\section{WESTERN BLOT ANALYSIS}

Protein samples were separated on 15\% SDS-PAGE gels and transferred to a $0.45 \mu$ polyvinylidene difluoride membrane (Millipore) equilibrated in transfer buffer (192 mM glycine, $25 \mathrm{mM}$ Tris, $0.05 \%$ SDS, $10 \%$ methanol) using an electrophoretic transfer cell for $90 \mathrm{~min}$ at $100 \mathrm{~V}$. After incubation with 5\% non-fat milk in $1 \times$ PBS for $2.5 \mathrm{~h}$, membranes were incubated with either mouse monoclonal anti-Cx45 (1:2,000, Cx45CR1 clone P3C9, Fred Hutchinson Cancer Center) or anti-His (1:2,000, His-Tag 27E9, Cell Signaling Technology, gift from Dr. Surinder Batra) for $16 \mathrm{~h}, 4^{\circ} \mathrm{C}$. Membranes were washed four times at room temperature with washing buffer (0.1\% Tween-20 in $1 \times$ PBS) for $10 \mathrm{~min}$. Membranes were then incubated with goat antimouse IgG secondary antibody horseradish peroxidase conjugates (1:12,000, 12-349, Millipore) for $1 \mathrm{~h}, 25^{\circ} \mathrm{C}$, then washed again. Bound antibodies were visualized using SuperSignal West Femto (Thermo Scientific).

\section{NUCLEAR MAGNETIC RESONANCE SPECTROSCOPY}

All NMR data were acquired using a $600 \mathrm{MHz}$ Varian INOVA NMR Spectrometer outfitted with a cryo-probe at the University of Nebraska Medical Center's NMR Facility. NMR spectra were processed and phased using NMRPipe and NMRDraw (Delaglio et al., 1995) and analyzed using NMRView (Johnson, 2004). Gradient-enhanced two-dimensional ${ }^{15} \mathrm{~N}$-HSQC experiments were acquired with 1,024 complex points in the direct dimension and 256 complex points in the indirect dimension (Kay et al., 1992). Sweep widths were $10,000 \mathrm{~Hz}$ in the ${ }^{1} \mathrm{H}$ dimension and $2,430.6 \mathrm{~Hz}$ in the ${ }^{15} \mathrm{~N}$ dimension.

\section{CIRCULAR DICHROÏSM SPECTROSCOPY}

Circular dichroïsm experiments were performed using a Jasco J-815 spectrophotometer fitted with a Peltier temperature control system. For each sample, five scans (wavelength range: 300$190 \mathrm{~nm}$; response time: $1 \mathrm{~s}$; scan rate: $50 \mathrm{~nm} / \mathrm{min}$; bandwidth $1.0 \mathrm{~nm}$ ) were collected using a $0.01 \mathrm{~cm}$ quartz cell and processed using Spectra Analysis (Jasco). Each spectrum is shown as the mean residue ellipticity (MRE; deg $\mathrm{cm}^{2} \mathrm{dmol}^{-1}$ ) as a function of wavelength and average of five scans. All spectra were corrected by subtracting the solvent spectrum. Protein concentrations were determined using a NanoDrop 1000 (Thermo Scientific) or Biospec 1601 UV-VIS spectrophotometer (Shimadzu) at $280 \mathrm{~nm}$. Analyses of spectra were accomplished using the Provencher and Glöckner method with the SP175 reference set on the online program DichroWeb (Provencher and Glöckner, 1981; Whitmore and Wallace, 2004; Lees et al., 2006).

\section{RESULTS}

\section{BACTERIAL STRAINS USED FOR PROTEIN EXPRESSION}

The E. coli strains BL21(DE3), C41(DE3), C43(DE3), and Rosetta 2(DE3)pLysS (chloramphenicol resistance) were transformed with the TM4-Cx45CT plasmid and incubated in lysogeny broth (LB) medium at $37^{\circ} \mathrm{C}, 250 \mathrm{rpm}$. Rosetta 2(DE3)pLysS expresses seven rare codons (Arg, AGA, AGG, CGA, CGG; Ile, AUA; Pro, CCC, Leu, CUA) in comparison to the BL21-Codon Plus(DE3)-RIPL strain (contains the most amount of tRNA genes in the BL21Codon Plus series), which contains only five tRNA genes (Arg, AGA, AGG; Ile, AUA; Pro, CCC, Leu, CUA). The TM4-Cx45CT contains five Arg rare codons, including two CGA, which the BL21Codon Plus(DE3)-RIPL strain does not have the corresponding tRNA. Therefore, Rosetta 2(DE3)pLysS was chosen as the representative strain that expresses rare codons for this study. Protein expression was induced by the addition of $1.0 \mathrm{mM} \mathrm{IPTG}$ (final concentration; Bioexpress) at an optical density of 0.6 at $600 \mathrm{~nm}$. The electrophoretic profile of total cellular proteins obtained $4 \mathrm{~h}$ after induction indicated that only C41(DE3) and C43(DE3) expressed TM4-Cx45CT (Figure 2, lanes 5 and 7, respectively). However, this protein yield is not optimal as significantly less protein per liter was produced then what was needed for the TM4-Cx43CT NMR structural studies (Kellezi et al., 2008). Upon examination of the TM4-Cx45CT gene sequence, 14 rare codons were identified; of these, eight (two in tandem) translate to the amino acid with the greatest codon bias, Arg (Table 2). Even though the Rosetta 2(DE3)pLysS strain was unable to express TM4-Cx45CT (Figure 2, lane 13), we hypothesized that expression would be enhanced by combining the pLysS plasmid with the C41(DE3) or C43(DE3) strains.

\section{EXPRESSION OF TM4-Cx45CT WITH THE pLysS PLASMID}

The pLysS (also referred to as pLysSRARE2) plasmid was isolated from Rosetta 2(DE3)pLysS cells using the QIAprep Spin Miniprep Kit (Qiagen) and co-transformed with the TM4-Cx45CT plasmid into the C41(DE3) and C43(DE3) strains. The cells were grown and induced as described above. The electrophoretic profile of 


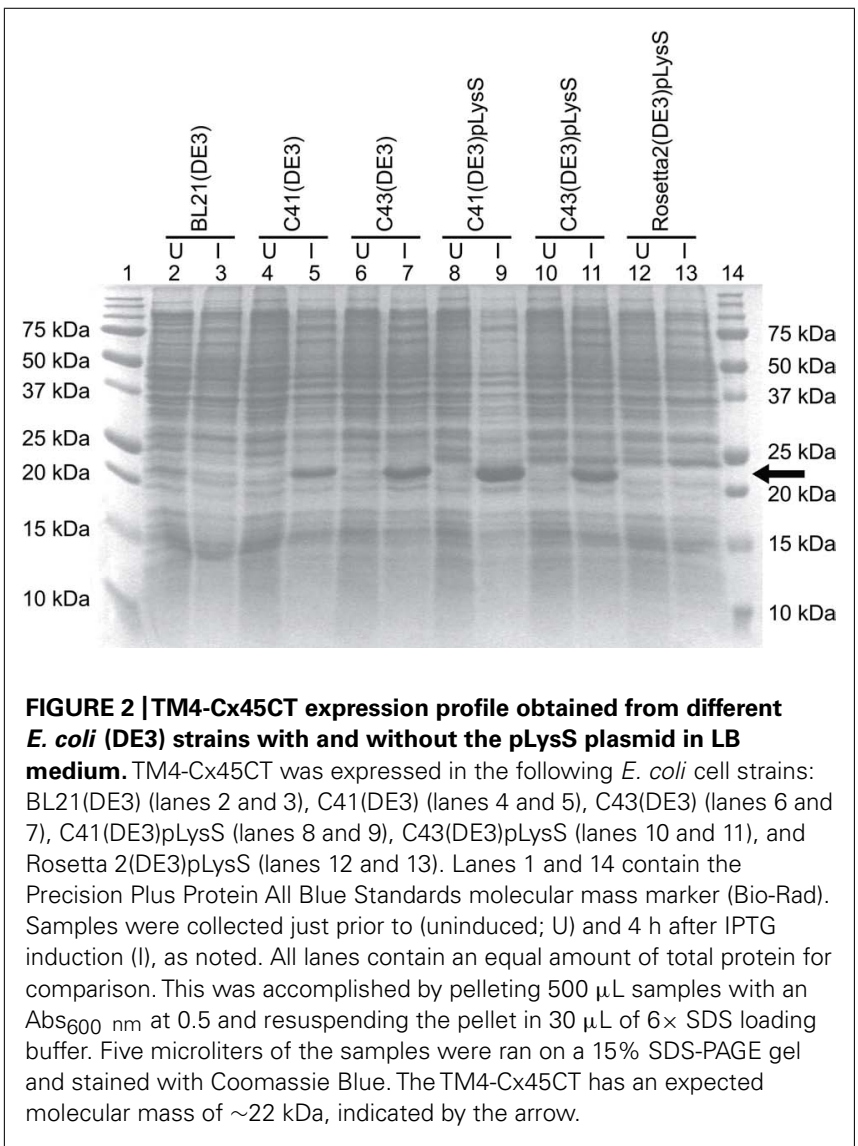

total cellular proteins obtained $4 \mathrm{~h}$ after induction showed that TM4-Cx45CT expression in C43(DE3) was similar with and without transformation of the pLysS plasmid (Figure 2, lanes 7 and 11, respectively). Conversely, TM4-Cx45CT expression was significantly increased in the C41(DE3)pLysS strain as compared to C41(DE3) alone (Figure 2, lanes 9 and 5, respectively). The expression was quantified by densitometry and revealed that the addition of the pLysS plasmid increased TM4-Cx45CT expression by $70 \%$ in C41(DE3). The expression of TM4-Cx45CT was confirmed by Western blot analyses using anti-His6 and anti-Cx45 antibodies (Figure 3).

Expression using the C41(DE3)pLysS strain was tested in isotopically labeled M63 minimal medium, which allows the control of nitrogen and carbon sources needed for NMR structural studies. The TM4-Cx45CT expression level decreased 84\% in M63 as compared to LB (Figure 4, lanes 6 and 3, respectively). However, expression was restored to LB level when M63 was supplemented with ${ }^{15} \mathrm{~N}$-ISOGRO ( $1 \mathrm{~g} / \mathrm{L}$, Isotec; Figure 4, lane 9). ISOGRO is an algal lysate-derived complex labeling medium that provides cells a metabolic boost that often decreases lag time, facilitates the attainment of growth saturation, and promotes recombinant protein production. ISOGRO helps cultures conserve cellular energy by limiting the requirement for de novo synthesis of cellular machinery and metabolic precursors; permitting more cellular resources to be direct toward recombinant protein expression. At this expression level, $8 \mathrm{~L}$ of growth is necessary to obtain
Table 2 | Rare codon usage for each TM4-CxCT domain.

\begin{tabular}{|c|c|c|c|c|c|c|}
\hline \multirow{2}{*}{$\begin{array}{l}\text { Connexin } \\
\text { isoform }\end{array}$} & \multicolumn{6}{|c|}{ Number of rare codons ${ }^{\ddagger}$} \\
\hline & Arginine & Isoleucine & Leucine & Proline & Total & Tandem \\
\hline TM4-Cx26CT & 0 AGG & 0 & 1 CTA & $2 \mathrm{CCC}$ & 4 & No \\
\hline \multirow[t]{2}{*}{ (D179-V226) } & $1 \mathrm{AGA}$ & & & & & \\
\hline & 0 CGA & & & & & \\
\hline TM4-C ×32CT & $0 \mathrm{AGG}$ & 1 ATA & 0 & $3 \mathrm{CCC}$ & 5 & No \\
\hline \multirow[t]{2}{*}{ (D178-C283) } & $1 \mathrm{AGA}$ & & & & & \\
\hline & $1 \mathrm{CGA}$ & & & & & \\
\hline TM4-CX37CT & $1 \mathrm{AGG}$ & 1 ATA & 0 & $8 \mathrm{CCC}$ & 15 & No \\
\hline \multirow[t]{2}{*}{ (D197-V333) } & 2 AGA & & & & & \\
\hline & 3 CGA & & & & & \\
\hline TM4-Cx40CT & $2 \mathrm{AGG}$ & 0 & 1 CTA & $4 \mathrm{CCC}$ & 8 & No \\
\hline \multirow[t]{2}{*}{ (N194-V356) } & 0 AGA & & & & & \\
\hline & $1 \mathrm{CGA}$ & & & & & \\
\hline TM4-Cx43CT & $1 \mathrm{AGG}$ & 0 & 0 & $2 \mathrm{CCC}$ & 7 & No \\
\hline \multirow[t]{2}{*}{ (D197-I382) } & 3 AGA & & & & & \\
\hline & $1 \mathrm{CGA}$ & & & & & \\
\hline TM4-CX45CT & $2 \mathrm{AGG}$ & 1 ATA & 3 CTA & $4 \mathrm{CCC}$ & 14 & Yes \\
\hline \multirow[t]{2}{*}{ (D219-|396) } & 2 AGA & & & & & \\
\hline & 2 CGA & & & & & \\
\hline TM4-Cx50CT & $5 \mathrm{AGG}$ & 2 ATA & 1 CTA & $3 \mathrm{CCC}$ & 12 & No \\
\hline \multirow[t]{2}{*}{ (D200-1440) } & $1 \mathrm{AGA}$ & & & & & \\
\hline & 0 CGA & & & & & \\
\hline
\end{tabular}

${ }^{\ddagger}$ Number of rare codons was determined using the Rare Codon Calculator (http://nihserver.mbi.ucla.edu/RACC/).

a $1 \mathrm{mM}$ at $300 \mu \mathrm{L}$ volume ("gold standard" concentration and volume for NMR structural studies; Table 1). This is in contrast to the 54 or $180 \mathrm{~L}$ would be necessary in M63 without ${ }^{15} \mathrm{~N}$-ISOGRO or without ${ }^{15} \mathrm{~N}$-ISOGRO and the pLys $\mathrm{plasmid}$, respectively.

Another advantage of using the pLysS plasmid is the suppression of T7 RNA polymerase expression prior to induction with IPTG. The phenotypes observed from "leaky" expression (before IPTG induction) of a membrane protein that is toxic to E. coli are a slow growth rate, low cell density, and in some cases, cell death. The TM4-Cx45CT expression was not toxic to the E. coli strains tested as the growth rates and final cell densities were identical with and without the pLysS plasmid (Figure 5), indicating that the benefit gained from the pLysS plasmid was solely the tRNAs expression.

\section{EXPRESSION OF OTHER TM4-CXCT CONSTRUCTS}

Outlined in Table 1 are the results from the other six connexin isoforms. With the exception of the TM4-Cx45CT, all of the constructs were able to grow in C41(DE3) cells. When comparing the primary sequences of the connexin isoforms, they all contain rare codons (Table 2). However, TM4-Cx45CT is the only construct that contains rare codons in tandem, which is known 

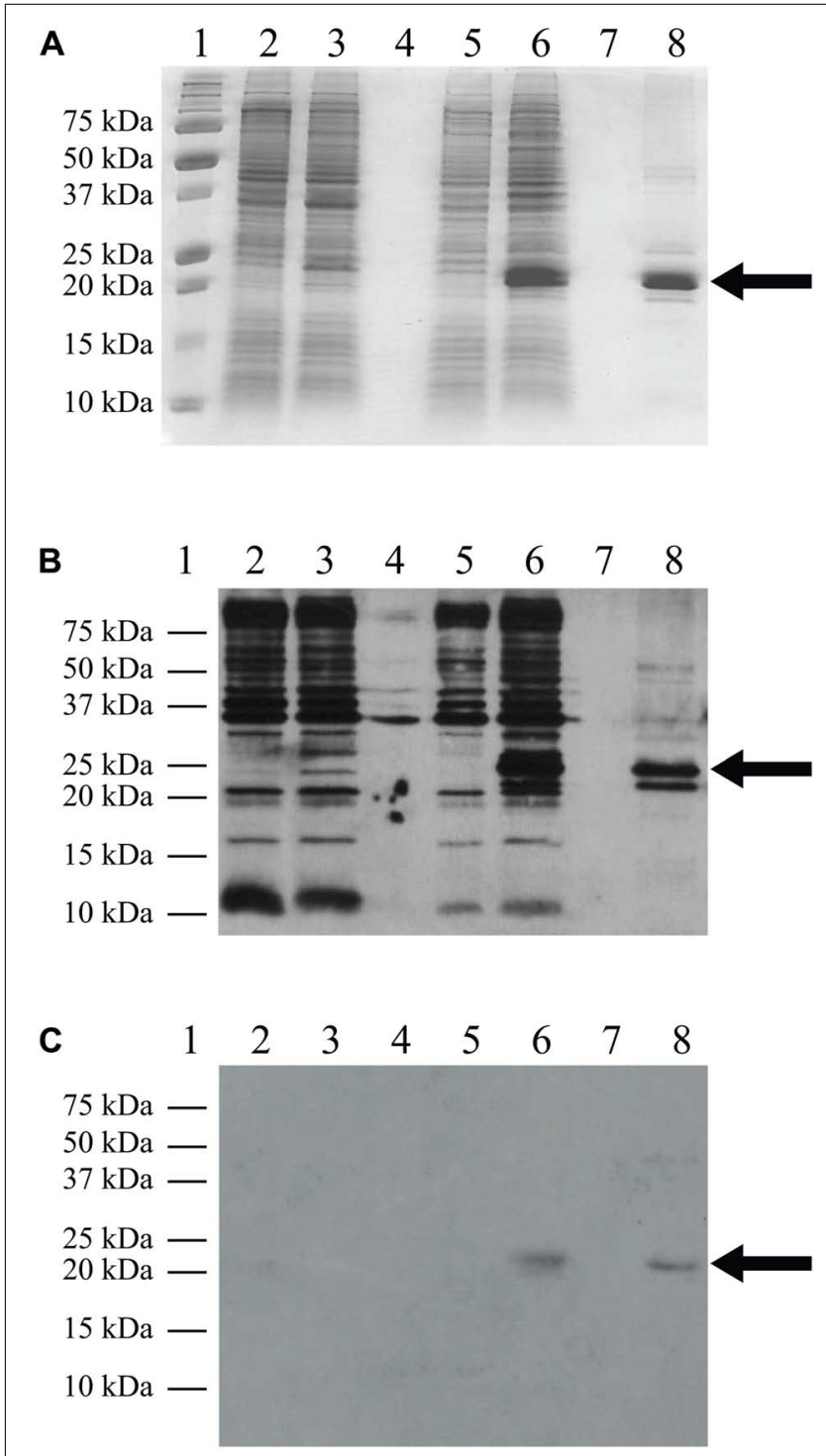

FIGURE 3 | Western blot analysis. C41(DE3)pLysS transformed with the empty pET-14b vector (lanes 2 and 3) or the TM4-Cx45CT plasmid (lanes 5 and 6). Lane 8 contains the TM4-Cx45CT after purification. Lane 1 contains the Precision Plus Protein All Blue Standards molecular mass marker (Bio-Rad) and lanes 4 and 7 are blank. Samples were collected just prior to (lanes 2 and 5) and $4 \mathrm{~h}$ after IPTG induction (lanes 3 and 6). A total of $500 \mu \mathrm{L}$ samples with an $\mathrm{Abs}_{600 \mathrm{~nm}}$ at 0.5 were pelleted and resuspended in $30 \mu \mathrm{L}$ of $6 \times$ SDS loading buffer. Equal amounts of total protein $(7 \mu \mathrm{L})$ were ran on a $15 \%$ SDS-PAGE gel. (A) Coomassie Blue stained gel is shown as a reference. Western blot analyses were performed using either (B) anti-His6, or (C) anti-Cx45 primary antibodies. The expected molecular mass of the TM4-Cx45CT is $\sim 22 \mathrm{kDa}$, which is indicated by the arrow. Of note, in (B) lane 8, the anti-His6 primary antibody also reacted with a $\sim 20$ Da protein. Although not present in the (A) 15\% SDS-PAGE gel or reactive with the $(\mathbf{C})$ anti-Cx45 primary antibody, we speculate the doublet is caused by proteolysis of the TM4-Cx45CT.

to inhibit protein expression (Kim and Lee, 2006). In addition, the TM4-Cx32CT, TM4-Cx37CT, and TM4-Cx50CT constructs were also able to grow in the C41(DE3)pLysS strain. In general, the TM4-CxCT constructs produced more protein in LB media

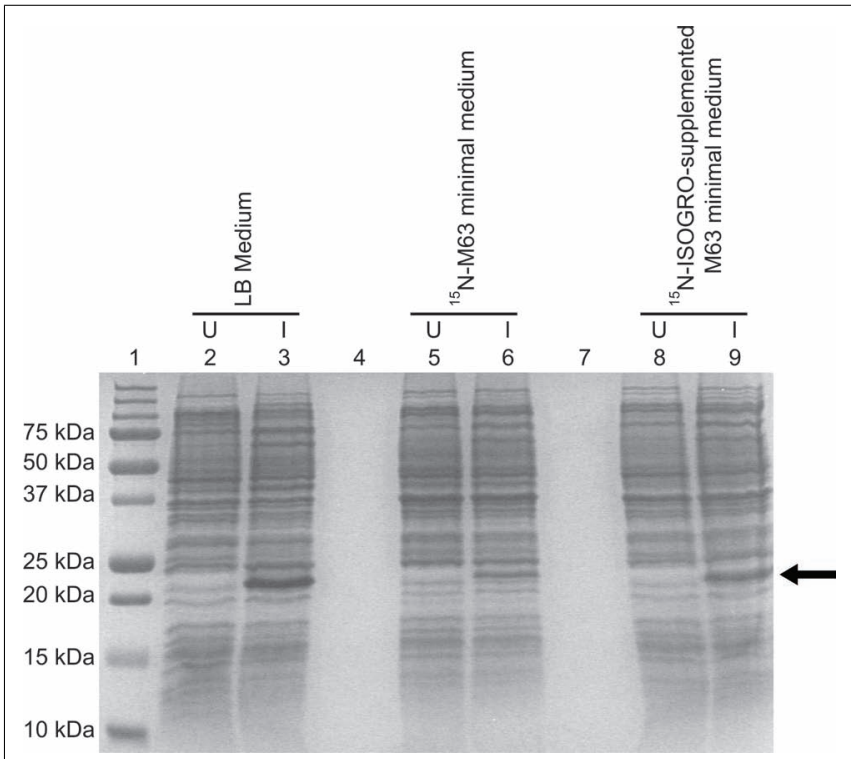

FIGURE 4 | Comparison of the TM4-Cx45CT expression profile obtained from $E$. coli strain $C 41$ (DE3) with the pLysS plasmid in LB and minimal media. C41(DE3)pLysS transformed with the TM4-Cx45CT plasmid was grown in LB medium (lanes 2 and 3), ${ }^{15} \mathrm{~N}$-labeled M63 minimal medium (lanes 5 and 6), and ${ }^{15} \mathrm{~N}$-labeled M63 minimal medium supplemented with $1 \mathrm{~g}{ }^{15} \mathrm{~N}$-ISOGRO/L medium (lanes 8 and 9). Lane 1 contains the Precision Plus Protein All Blue Standards molecular mass marker (Bio-Rad) and lanes 4 and 7 are blank. Samples were collected just prior to (uninduced, U) and $4 \mathrm{~h}$ after IPTG induction (I), as noted. A total of $500 \mu \mathrm{L}$ samples with an $\mathrm{Abs}_{600 \mathrm{~nm}}$ at 0.5 were pelleted and resuspended in $30 \mu \mathrm{L}$ of $6 \times$ SDS loading buffer. Equal amounts of total protein $(7 \mu \mathrm{L})$ were ran on a $15 \%$ SDS-PAGE gel and stained with Coomassie Blue. The TM4-Cx45CT has an expected molecular mass of $\sim 22 \mathrm{kDa}$, indicated by the arrow.

(e.g., for CD, ITC, etc.) as compared with minimal media (i.e., for NMR). The only differences were the TM4-Cx43CT isoform grew equally as well and the TM4-Cx45CT grew better in minimal media, which is caused by the addition of ${ }^{15} \mathrm{~N}$-ISOGRO to the media.

\section{CHARACTERIZATION OF THE TM4-CX45CT SECONDARY STRUCTURE}

Combining a plasmid that expresses rare tRNAs with an E. coli strain selected to express toxic membrane proteins improved the yield of TM4-Cx45CT to levels that are cost-effective and now feasible for NMR structural studies. Using the expression protocol developed herein, the TM4-Cx45CT was purified and reconstituted into detergent micelles (LPPG) using techniques developed previously for the TM4-Cx43CT construct (Kellezi et al., 2008). The purity of the TM4-Cx45CT was verified by SDS-PAGE and Western blot analyses (Figure 3, Lane 8). Next, a ${ }^{15} \mathrm{~N}-\mathrm{HSQC}$ spectrum was collected to evaluate the sample properties of the TM4-Cx45CT. The ${ }^{15} \mathrm{~N}$-HSQC is a two-dimensional NMR experiment in which each amino acid except proline gives one signal, or chemical shift, that corresponds to the $\mathrm{N}-\mathrm{H}$ amide group. Figure 6A shows the ${ }^{15} \mathrm{~N}-\mathrm{HSQC}$ for TM4-Cx45CT collected in $20 \mathrm{mM}$ MES, $1 \mathrm{mM}$ DTT, 8\% LPPG, and $1 \mathrm{mM}$ EDTA. Unexpectedly, the spectra quality is poor, and only approximately $50 \%$ of the expected cross peaks are present. Previous studies identified that a soluble version of the Cx45CT (K265-I396) was in a dimer 
A

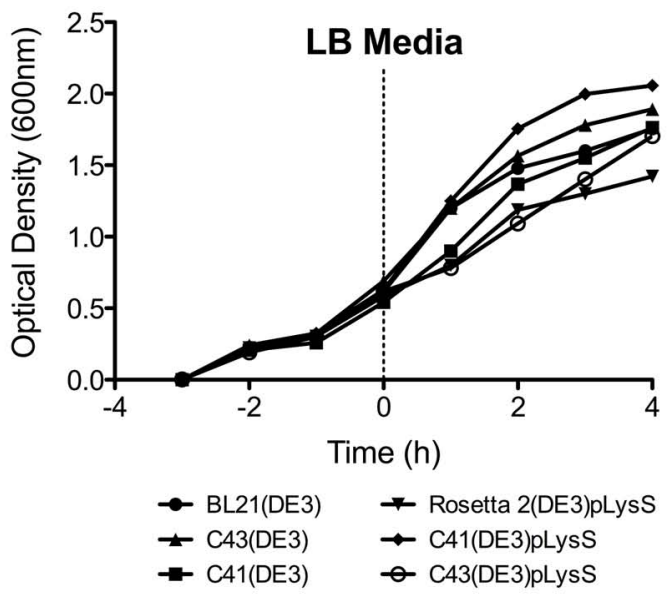

B

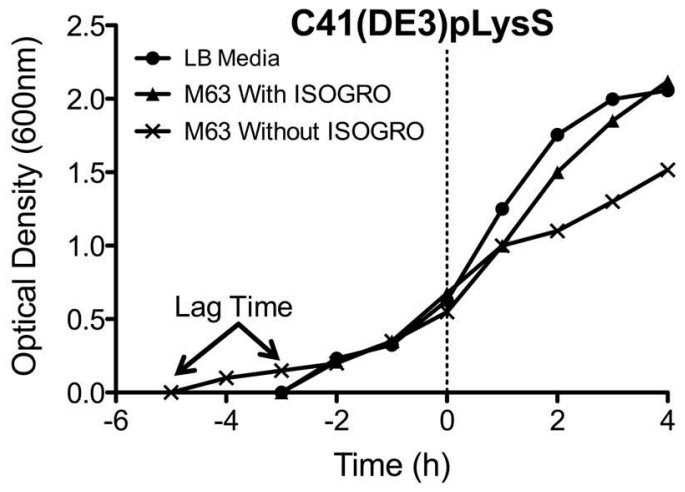

FIGURE 5 | Growth curves of the TM4-Cx45CT. (A) Optical density of cultures in LB media were monitored at $\mathrm{Abs}_{600} \mathrm{~nm}$ during the growth of TM4-Cx45CT in six different E. coli strains. (B) TM4-Cx45CT grown in the C41(DE3)pLysS stain using LB and M63 minimal media with or without ISOGRO. The dashed line at $0 \mathrm{~h}$ represents the induction with IPTG.

conformation that could be disrupted by acetonitrile (Kopanic and Sorgen, 2012). Therefore, a ${ }^{15} \mathrm{~N}$-HSQC spectrum was collected in the presence of $30 \%$ acetonitrile (Figure 6B), which shows the total number (168) of expected amide cross peaks corresponding to the non-proline residues of the TM4-Cx45CT. Additionally, the number of Gly residues (12, circled and numbered) matches the number found in the primary sequence and indicates that the TM4-Cx45CT construct is in a single conformation. Altogether, this demonstrates the feasibility of solving the monomeric TM4-Cx45CT structure.

Circular dichroïsm was used to gain insight into the TM4Cx45CT secondary structure before obtaining an atomic level structure. Intracellular acidification is a major consequence of tissue ischemia during a myocardial infarction, which leads to closure and degradation of gap junction channels and can be a substrate for malignant ventricular arrhythmias (Lau, 2005). Therefore, data were collected at either physiological ( $\mathrm{pH} 7.5)$ or ischemic $(\mathrm{pH} 5.8)$ conditions (Figure 7). The TM4-Cx45CT (without acetonitrile) has a small increase in $\alpha$-helical content under acidic conditions
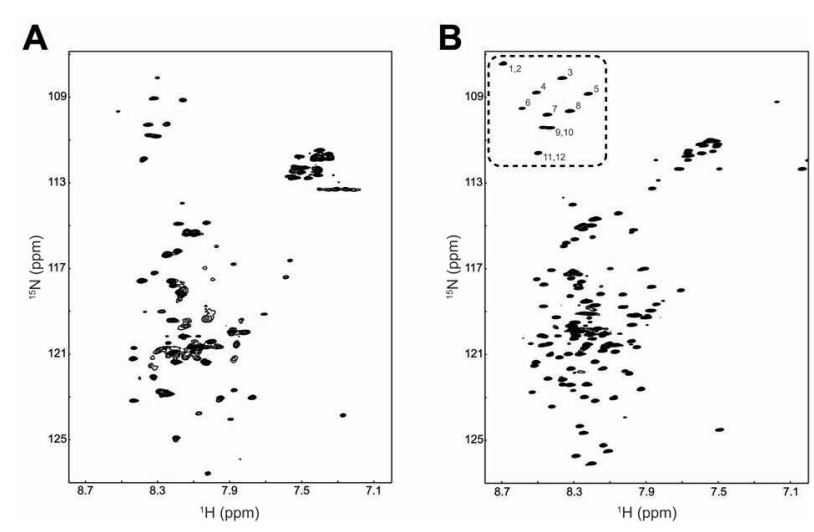

FIGURE 6 | Demonstrating the feasibility of solving the TM4-Cx45CT structure. ${ }^{15} \mathrm{~N}-\mathrm{HSQC}$ of the TM4-Cx45CT in $20 \mathrm{mM} \mathrm{MES}, 1 \mathrm{mM}$ DTT, $1 \mathrm{mM}$ EDTA, and 8\% 1-palmitoyl-2-hydroxy-sn-glycero-3-[phospho-RAC(1-glycerol)] detergent micelles (A) alone or (B) in the presence of $30 \%$ deuterated acetonitrile. Highlighted are the 12 Gly residues in the TM4-Cx45CT (dotted rectangle, numbered).

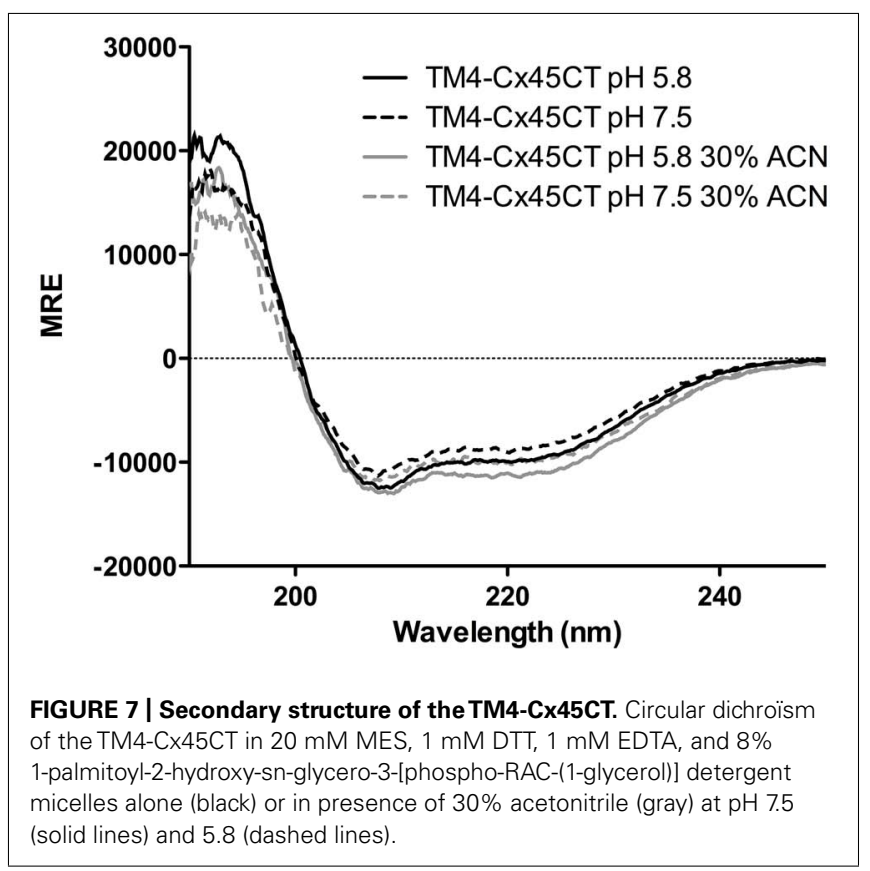

( $\mathrm{pH} 7.5,25 \%$; $\mathrm{pH} 5.8,28 \%$ ). This $\mathrm{pH}$-effect is similar in the presence of $30 \%$ acetonitrile with a small increase in overall $\alpha$-helical content ( $\mathrm{pH} 7.5$ 28\%; $\mathrm{pH} 5.8,32 \%$ ). The $\mathrm{pH}$-induced increase in $\alpha$-helical content for the TM4-Cx45CT (3-4\%) is smaller than observed for the TM4-Cx43CT (16\%; Kellezi et al., 2008; Grosely et al., 2012).

\section{DISCUSSION}

Even though the soluble versions of connexin CT domains have proven to be useful for describing mechanisms involved in gap junction regulation, several results indicate that these constructs may not be optimal. For example, the cryo-electron microscopy 
structure of the Cx43 mutant (truncated at residue T263) suggested that the N-terminal region of the CT domain (S255-T263) contains $\alpha$-helical structure (Unger et al., 1999). In contrast, the NMR data for the soluble Cx43CT (S255-I382) identified these same residues as weak resonances, suggesting an exchange between an unstructured and $\alpha$-helical conformations (Sorgen et al., 2004). Additionally, not all of the expected NOEs were observed in the two dynamic $\alpha$-helical regions of the soluble CT structure. The TM4-tethered Cx43CT protein (D219-I382) solubilized in detergent micelles offers a more native-like construct for structural studies (Kellezi et al., 2008). CD and NMR data indicated that the TM4-Cx43CT has more $\alpha$-helical content than can be attributed to solely the addition of the TM4 domain to the soluble CT domain (Kellezi et al., 2008; Grosely et al., 2012). In addition, the TM4-Cx43CT is also structurally

\section{REFERENCES}

Bernaudat, F., Frelet-Barrand, A., Pochon, N., Dementin, S., Hivin, P., Boutigny, S., et al. (2011). Heterologous expression of membrane proteins: choosing the appropriate host. PLOS ONE 6:e29191. doi: 10.1371/journal.pone.0029191

Betsuyaku, T., Nnebe, N. S., Sundset, R., Patibandla, S., Krueger, C. M., and Yamada, K. A. (2005). Overexpression of cardiac connexin 45 increases susceptibility to ventricular tachyarrhythmias in vivo. Am. J. Physiol. Heart Circ. Physiol. 290, H163-H171. doi: 10.1152/ajpheart. 01308.2004

Delaglio, F., Grzesiek, S., Vuister, G. W., Zhu, G., Pfeifer, J., and Bax, A. (1995). NMRPipe: a multidimensional spectral processing system based on UNIX pipes. J. Biomol. NMR 6, 277-293. doi: 10.1007/BF00197809

Drew, D., Fröderberg, L., Baars, L., and de Gier, J.-W. L. (2003). Assembly and overexpression of membrane proteins in Escherichia coli. Biochim. Biophys. Acta 1610, 310. doi: 10.1016/S0005-2736(02) 00707-1

Gouy, M., and Gautier, C. (1982). Codon usage in bacteria: correlation with gene expressivity. Nucleic Acids Res. 10, 7055-7074. doi: 10.1093/nar/10.22.7055

Grosely, R., Kieken, F., and Sorgen, P. L. (2012). (1)H, (13)C, and (15)N backbone resonance assignments of the connexin 43 carboxyl terminal domain attached to the 4th transmembrane domain in detergent micelles. Biomol. NMR Assign. doi: 10.1007/s12104-0129432-8 [Epub ahead of print].

Grosely, R., Kopanic, J. L., Nabors, S., Kieken, F., Spagnol, G., Al-Mugotir, M., et al. (2013). Effects of phosphorylation on the structure and backbone dynamics of the intrinsically disordered Connexin43 carboxylterminal domain. J. Biol. Chem. doi: 10.1074/jbc.M113.454389 [Epub ahead of print].

Gustafsson, C., Govindarajan, S., and Minshull, J. (2004). Codon bias and heterologous protein expression. Trends Biotechnol. 22, 346353. doi: 10.1016/j.tibtech.2004. 04.006

Johnson, B. A. (2004). Using NMRView to visualize and analyze the NMR spectra of macromolecules. Methods Mol. Biol. 278, 313-352. doi: 10.1385/1-59259-809-9:313

Kane, J. F. (1995). Effects of rare codon clusters on high-level expression of heterologous proteins in Escherichia coli. Curr. Opin. Biotechnol. 6, 494-500. doi: 10.1016/09581669(95)80082-4

Kay, L., Keifer, P., and Saarinen, T. (1992). Pure absorption gradient enhanced heteronuclear single quantum correlation spectroscopy with improved sensitivity. J. Am. Chem. Soc. 114, 10663-10665. doi: 10.1021/ja00052a088

Kellezi, A., Grosely, R., Kieken, F., Borgstahl, G. E. O., and Sorgen, P. L. (2008). Purification and reconstitution of the connexin 43 carboxyl terminus attached to the 4 th transmembrane domain in detergent micelles. Protein Expr. Purif. 59, 215222. doi: $10.1016 /$ j.pep.2008.01.023

Kim, S., and Lee, S. B. (2006). Rare codon clusters at $5^{\prime}$-end influence heterologous expression of archaeal gene in Escherichia coli. Pro10.1016/j.pep.2006.07.014

Kopanic, J. L., and Sorgen, P. L. (2012). Chemical shift assignments of the connexin 45 carboxyl terminal domain: monomer and dimer conformations. Biomol. NMR Assign. doi: 10.1007/s12104-0129431-9 [Epub ahead of print]. tein Expr. Purif. 50, 49-57. doi:

responsive to the changes in $\mathrm{pH}$ and phosphorylation, unlike the soluble $\mathrm{Cx} 43 \mathrm{CT}$, indicating that this construct is a better model for the investigation of structural-based mechanisms behind gap junction channel regulation (Kellezi etal., 2008; Grosely et al., 2012). Extending this study to other connexin isoforms, such as Cx45, will allow future structural studies to characterize mechanisms of gap junction regulation. The motivation behind this study is that a better understanding of the similarities and differences in structure between connexin CT domains when attached to the TM4 can be exploited to aid in the design of chemical modifiers.

\section{ACKNOWLEDGMENT}

This work was supported by United States Public Health Service Grant GM072631.

Kurland, C., and Gallant, J. (1996). Errors of heterologous protein expression. Curr. Opin. Biotechnol. 7, 489-493. doi: 10.1016/ S0958-1669(96)80050-4

Laible, P. D., Scott, H. N., Henry, L., and Hanson, D. K. (2004). Towards higher-throughput membrane protein production for structural genomics initiatives. J. Struct. Funct. Genomics 5, 167-172. doi: 10.1023/ B:JSFG.0000029201.33710.46

Laird, D. W. (2010). The gap junction proteome and its relationship to disease. Trends Cell Biol. 20, 92-101. doi: 10.1016/j.tcb.2009.11.001

Lau, A. F. (2005). c-Src: bridging the gap between phosphorylationand acidification-induced gap junction channel closure. Sci. STKE 2005 , pe33. doi: 10.1126/stke.2912005pe33

Lees, J. G., Miles, A. J., Wien, F., and Wallace, B. A. (2006). A reference database for circular dichroism spectroscopy covering fold and secondary structure space. Bioinformatics 22 1955-1962. doi: 10.1093/bioinformatics/btl327

Miroux, B., and Walker, J. E. (1996). Over-production of proteins in Escherichia coli: mutant hosts that allow synthesis of some membrane proteins and globular proteins at high levels. J. Mol. Biol. 260, 289-298. doi: 10.1006/jmbi.1996.0399

Molina, D. M., Cornvik, T., Eshaghi, S., Haeggström, J. Z., Nordlund, P., and Sabet, M. I. (2008). Engineering membrane protein overproduction in Escherichia coli. Protein Sci. 17, 673-680. doi: 10.1110/ps. 073242508

Novy, R., Drott, D., Yaeger, K., and Mierendorf, R. (2001). Overcoming the codon bias of E. coli for enhanced protein expression. Innovations 12, $1-3$.

Palacios-Prado, N., Briggs, S. W., Skeberdis, V. A., Pranevicius, M.,
Bennett, M. V. L., and Bukauskas, F. F. (2010). pH-dependent modulation of voltage gating in connexin45 homotypic and connexin45/connexin43 heterotypic gap junctions. Proc. Natl. Acad. Sci. U.S.A. 107, 9897-9902. doi: 10.1073/ pnas. 1004552107

Provencher, S. W., and Glöckner, J. (1981). Estimation of globular protein secondary structure from circular dichroism. Biochemistry 20, 33-37. doi: 10.1021/bi00504a006

Ratelade, J., Miot, M. C., Johnson, E., Betton, J. M., Mazodier, P., and Benaroudj, N. (2009). Production of recombinant proteins in the ion-deficient BL21(DE3) strain of Escherichia coli in the absence of the DnaK chaperone. Appl. Environ. Microbiol. 75, 3803-3807. doi: 10.1128/AEM.00255-09

Severs, N. J., Dupont, E., Thomas, N., Kaba, R., Rothery, S., Jain, R., etal. (2006). "Alterations in cardiac connexin expression in cardiomyopathies," in Cardiovascular Gap Junctions: Advances in Cardiology, ed. S. Dhein (Basel: Karger), 228-242.

Sorgen, P. L., Duffy, H. S., Sahoo, P., Coombs, W., Delmar, M., and Spray, D. C. (2004). Structural changes in the carboxyl terminus of the gap junction protein connexin43 indicates signaling between binding domains for $\mathrm{c}-\mathrm{Src}$ and zonula occludens-1. J. Biol. Chem. 279, 54695-54701. doi: 10.1074/ jbc.M409552200

Studier, F. W., and Moffatt, B. A. (1986). Use of bacteriophage T7 RNA polymerase to direct selective high-level expression of cloned genes. J. Mol. Biol. 189, 113-130. doi: 10.1016/0022-2836(86)90385-2

Unger, V. M., Kumar, N. M., Gilula, N. B., and Yeager, M. (1999). Three-dimensional structure of a 
recombinant gap junction membrane channel. Science 283, 1176-1180. doi: 10.1126/science.283.5405.1176

Whitmore, L., and Wallace, B. A. (2004). DICHROWEB, an online server for protein secondary structure analyses from circular dichroism spectroscopic data. Nucleic Acids Res. 32, W668-W673. doi: 10.1093/nar/gkh371

Yamada, K. A., Rogers, J. G., Sundset, R., Steinberg, T. H., and Saffitz, J. E. (2003). Up-regulation of connexin45 in heart failure. $J$.
Cardiovasc. Electrophysiol. 14, 12051212. doi: 10.1046/j.1540-8167.2003. 03276.x

Zoidl, G., and Dermietzel, R. (2010). Gap junctions in inherited human disease. Pflugers Archiv. 460, 451-466. doi: 10.1007/s00424-010-0789-1

Conflict of Interest Statement: The authors declare that the research was conducted in the absence of any commercial or financial relationships that could be construed as a potential conflict of interest.
Received: 14 May 2013; accepted: 07 August 2013; published online: 23 August 2013.

Citation: Kopanic JL, Al-Mugotir M, Zach S, Das S, Grosely $R$ and Sorgen PL (2013) An Escherichia coli strain for expression of the connexin 45 carboxyl terminus attached to the 4 th transmembrane domain. Front. Pharmacol. 4:106. doi: 10.3389/fphar.2013.00106

This article was submitted to Pharmacology of Ion Channels and Channelopathies, a section of the journal Frontiers in Pharmacology.
Copyright $\odot 2013$ Kopanic, Al-Mugotir, Zach, Das, Grosely and Sorgen. This is an open-access article distributed under the terms of the Creative Commons Attribution License (CC BY). The use, distribution or reproduction in other forums is permitted, provided the original author(s) or licensor are credited and that the original publication in this journal is cited, in accordance with accepted academic practice. No use, distribution or reproduction is permitted which does not comply with these terms. 